\title{
PENGARUH PEMBERIAN PAKAN KOMPLIT BERBASIS HASIL SAMPING UBI KAYU KLON TERHADAP PERTUMBUHAN DOMBA JANTAN LOKAL
}

\section{(Effect of Complete Feed Base on Cassava by Product on Performance of Local Sheep)}

\author{
Janwar Hamonangan Tampubolon ${ }^{1}$, R.Edhy Mirwandhono ${ }^{2}$ dan Ma'ruf Tafsin ${ }^{2}$
}

1. Mahasiswa Program studi Peternanakan Fakultas Pertanian Universitas Sumatera utara

2. Staf Pengajar Studi Peternakan Fakultas Pertanian Universitas Sumatera Utara

\begin{abstract}
Cassava by products and there product industrial potential as feed sheep for complete feed. The research was conducted at the University of Sumatra utara, Faculty of Agriculture started from September until December 2013. This research objective to assess the effect of complete feed based on cassava by product on the feed intake, daily gain and feed conversion ratio of local sheep. The research method used in this study was a completely randomized design (CRD) with 3 treatments and 4 replications. This treatment consists of P1: (100\% grass); P2 (50\% grass and 50\% complete feed base on cassava); (P3 100\% complete feed base on cassava). The results showed that the average feed intake (g/head/day) for treatments P0, P1 and P2 were 518.27, 316.20 and 255.13, respectively, while on the average growth of body weight (g/head/day) were 33.73; 39.3 and 55.50, respectively, and feed conversion ratio were 15.44; 8.04; and 4.70. The statistical test showed that feeding complete feed base on cassava significantly different effect $(P<0,01)$ on feed intake, daily gain and feed conversion ratio. The conclusion decrease feed intake, improve daily gain, and lower feed conversion ratio. complete feed based by product of cassava can be given $100 \%$ of the sheep.
\end{abstract}

Keywords : Cassava, by product, sheep, performance.

\begin{abstract}
ABSTRAK
Hasil samping ubi kayu dan industrinya berpotensi sebagai bahan baku pakan komplit domba. Penelitian ini bertujuan untuk mengetahui pengaruh pemberian pakan komplit berbasis hasil samping ubi kayu terhadap konsumsi, pertambahan bobot badan, dan konversi pakan domba jantan lokal dengan rataan bobot badan awal 7.75 \pm 1.75 . Penelitian dilaksanakan di Fakultas pertanian Univesitas Sumatera Utara pada bulan September sampai Desember 2013. Rancangan yang digunakan dalam penelitaian ini adalah rancangan acak lengkap (RAL) dengan 3 perlakuan dan 4 ulangan. Perlakuan ini terdiri atas P1: (100\% rumput); P2( 50\% rumput dan 50\% pellet hasil samping ubi kayu); (P3 100\% pakan hasil samping ubi kayu). Hasil penelitian menunjukan rataan konsumsi pakan (g/ekor/hari) 518.27, 316.20 dan 255.13. rataan pertumbuhan bobot badan (g/ekor/hari) 33,73; 39,3 dan 55.50. Konversi pakan 15,$44 ; 8,04 ; 4,70$. Uji statistik menunjukkan bahwa pemberian pakan berbasis hasil samping ubi kayu berpengaruh sangat nyata menurunkan konsumsi pakan, meningkatkan pertambahan bobot badan, dan menurunkan konversi pakan. Kesimpulan dari hasil penelitian pemberian pakan berbasis hasil samping ubi kayu memberikan pengaruh sangat nyata menurunkan konsumsi, meningkatkan pertambahan bobot badan, dan menurunkan konversi. Pakan pellet berbasis hasil samping ubi kayu dapat diberikan $100 \%$ terhadap domba.
\end{abstract}

Kata kunci : Ubi kayu, hasil samping, domba lokal, performans. 


\section{PENDAHULUAN}

Optimalisasi pemanfaatan hasil samping pertanian merupakan strategi yang harus dilakukan untuk memenuhi kebutuhan pangan. Pemanfaatan hasil samping ubi kayu sebagai bahan pakan ternak merupakan potensi yang prospek untuk dikembangkan. Melihat semakin meluasnya lahan pertanian yang digunakan sebagai ladang ubi kayu di daerah Indonesia khususnya di Sumatera Utara menjadi hal yang menjanjikan sebagai sumber pangan dan pakan yang berkelanjutan.

Pakan merupakan biaya terbesar dari seluruh biaya produksi, yaitu sekitar 70-80\% (Wahyu, 1988). Pemanfaatan bahan pakan lokal produk pertanian ataupun hasil ikutannya dengan optimal diharapkan dapat mengurangi biaya pakan. Dengan demikian, diperlukan suatu upaya untuk mencari alternatif bahan pakan yang murah, mudah didapat, kualitasnya baik, serta tidak bersaing dengan kebutuhan manusia. Salah satunya adalah daun, kulit ubi kayu dan hasil samping agroindustri ubi kayu.

Produksi ubi kayu di Indonesia mengalami peningkatan yang cukup pesat dalam lima tahun terakhir ini dari 19.321.183 ton pada tahun 2005 menjadi 21.786.691 pada tahun 2009, atau mengalami peningkatan sebesar 11,32\% (Departemen Pertanian, 2009). Peningkatan produksi tersebut menyebabkan hasil samping pengolahan ubi kayu dan industrinya juga meningkat sehingga cukup potensial digunakan sebagai pakan. Bahan pakan yang berasal dari hasil samping pascapanen tanaman ubi kayu antara lain pucuk ubi kayu, batang ubi kayu, kulit ubi kayu dan onggok tergolong sebagai pakan sumber karbohidrat mudah dicerna.

Pemanfaatan hasil samping ubi kayu sebagai sumber bahan pakan ternak masih sangat sedikit sementara perkembangan peternakan terus meningkat dengan laju pertumbuhan 12,9\%/ tahun. Meningkatnya produksi hasil samping tanaman dan produksi ubi kayu tersebut dapat dimanfaatkan sebagai pakan pengganti hijauan yang ketersediaanya semakin terbatas. Dengan demikian, pemanfaatan hasil samping tanaman pangan merupakan salah satu solusi untuk mengembangkan peternakan.

Sehubungan dengan letak geografis Sumatera Utara yang cukup strategis telah membuka peluang untuk masuknya produk peternakan diantaranya daging baik dari beberapa propinsi lain maupun dari luar negeri. Hal tersebut dimungkinkan karena Sumatera Utara harus memenuhi permintaan lokal yang sampai saat ini masih belum dapat dipenuhi sendiri. Selain itu dengan 
masuknya era pasar bebas telah membuka peluang masuknya produk peternakan asing baik yang legal maupun ilegal. Data dari dinas peternakan propinsi, menunjukkan bahwa Sumatera Utara masih kekurangan daging setara dengan 10.000 ekor sapi setiap tahunnya. Kondisi tersebut dapat menjadikan dorongan bagi Sumatera Utara untuk dapat mengembangkan industri peternakan dengan menekan potensi sumber daya lokal serta mendorong partisipasi penanam modal setempat.

Berdasarkan zonasi agroekologi terhadap wilayah pertanian Sumatera Utara menunjukkan bahwa ekosistem lahan kering dataran rendah (LKDR) merupakan prioritas pengembangan karena merupakan luas wilayah terbesar (1,3 juta hektar) dan merupakan sentra produksi berbagai komoditas pertanian dataran rendah meliputi ternak ruminansia (kambing, domba dan sapi), tanaman pangan (ubi kayu dan kedelai). Kondisi sumberdaya yang tersedia tersebut telah membuka peluang yang sangat luas untuk pengembangan ternak yang terintegrasi.

Pakan komplit merupakan pakan alternatif pengganti hijauan. Meningkatnya pertumbuhan jumlah peduduk menjadikan daerah padang penggebalaan banyak beralih fungsi menjadi pemukiman,lahan perkebunan, lahan pertanian. Seiring dengan peralihan sistem tersebut hijauan semakin sedikit dan susah dicari.

\section{BAHAN DAN METODE PENELITIAN}

\section{Lokasi dan Waktu Penelitian}

Penelitian telah dilaksanakan di Laboratorium Biologi Ternak Program Studi Peternakan Fakultas Pertanian Universitas Sumatera Utara. Penelitian berlangsung selama 4 bulan di mulai dari September 2013 sampai Desember 2013.

\section{Bahan dan Alat}

Domba yang digunakan dalam penelitian ini adalah sebanyak 12 ekor domba dengan rataan bobot badan $(7,75 \pm 1.75 \mathrm{~kg})$, ransum terdiri dari kulit buah ubi kayu, batang muda ubi kayu, BIS, garam, daun ubi kayu dan molases, air minum dberikan secara adlibitum, obat-obatan seperti obat cacing (kalbazen), anti bloat (kembung) dan vitamin.

Kandang individual 12 unit beserta perlengkapannya, tempat pakan dan minumnya masing-masing 12 buah, timbangan bobot hidup berkapasitas $50 \mathrm{~kg}$ dengan kepekaan $50 \mathrm{~g}$, timbangan berkapasitas $2 \mathrm{~kg}$ dengan kepekaan $10 \mathrm{~g}$ untuk menimbang pakan, mesin penggiling 
pakan (chopper), alat pembersih kandang seperti sapu lidi, sekop, pisau dan cutter, ember, plastik, alat tulis, buku data dan kalkulator.

\section{Metode penelitian}

Metode yang digunakan adalah rancangan acak lengkap (RAL) non faktorial dengan 3 perlakuan 4 ulangan, yaitu:

P0: Pemberian pakan menggunakan hijauan

P1: Pemberian pakan menggunakan pakan komplit dengan hijauan

P2: Pemberian pakan menggunakan pakan komplit

Metode linier percobaan yang digunkan adalah :

Yij $\quad=\mu+\alpha i+€ j$

Keterangan:

$\mathrm{i} \quad=1,2,3, \ldots . \mathrm{t}($ perlakuan $)$

$\mathrm{j} \quad=1,2,3, \ldots . \mathrm{r}($ ulangan $)$

Yij = nilai pengamatan yang diperoleh dari satu perlakuan ke-I dan ulangan ke-j

$\mu \quad=$ efek nilai tengah

$\alpha \mathrm{i}=$ efek perlakuan pada taraf ke-i

$\mathfrak{\epsilon i}=$ pengaruh galat percobaan taraf ke-I pada ulangan ke- $\mathrm{j}$

Tabel 1. Formulasi pakan

\begin{tabular}{lcccr}
\hline Perlakuan & P0 & P1 & \multicolumn{2}{c}{ P2 } \\
\hline Rumput & $100 \%$ & $50 \%$ & \multicolumn{2}{c}{0} \\
Pakan Komplit & 0 & $50 \%$ & \multicolumn{2}{c}{$100 \%$} \\
\hline Bahan Pakan & Formulasi & PK & SK & TDN \\
\hline Daun Ubi & 50.00 & 8.56 & 9.73 & 38.25 \\
Batang Muda & 20.00 & 1.23 & 7.59 & 12.95 \\
Onggok & 5.00 & 0.10 & 0.82 & 3.85 \\
BIS & 20.00 & 3.08 & 2.10 & 16.20 \\
Molases & 3.00 & 0.02 & 0.01 & 2.43 \\
Urea & 1.00 & 2.02 & 0.00 & 0.00 \\
Garam & 0.50 & 0.00 & 0.00 & 0.00 \\
Mineral & 0.50 & 0.00 & 0.00 & 0.00 \\
Jumlah & 100.00 & 15.02 & 20.25 & 73.68 \\
\hline
\end{tabular}




\section{Parameter Penelitian}

\section{Pertambahan Bobot Badan Harian}

Pertambahan bobot badan dihitung dengan cara membagi selisih bobot badan (bobot akhir - bobot awal) dengan lama hari penimbangan. Dilakukan selama satu minggu sekali, dinyatakan dengan gram per ekor per hari. (Sodiq dan Abidin,2002)

$$
\text { PBBH }=\frac{\text { bobot akhir }- \text { bobot awal (g/ekor) }}{\text { Lama pemeliharaan (hari) }}
$$

\section{Konsumsi Pakan}

Konsumsi pakan diperoleh dengan menghitung selisih jumlah pakan yang diberikan dengan sisa pakan setiap harinya dan dinyatakan dengan gram per ekor per hari. (Sodiq dan Abidin,2002)

Konsumsi Pakan $=$ Pakan yang diberikan $($ dalam \% BK) - Pakan yang sisa $($ dalam \% BK).

\section{Konversi pakan}

Konversi pakan dihitung dengan cara membagi angka rata - rata konsumsi bahan kering per ekor per hari dengan angka rata - rata produksi pertambahan bobot badan per ekor per hari. (Sodiq dan Abidin, 2002)

$$
\text { Konversi pakan }=\frac{\text { Pakan yang dikosumsi }}{\operatorname{PBBH}(\stackrel{\mathrm{g}}{-})}
$$

\section{HASIL DAN PEMBAHASAN}

Rataan dari ketiga parameter yaitu: konsumsi pakan, pertambahan bobot badan, dan konversi pakan selama penelitian dapat dilihat pada tabel berikut ini

Tabel 2 Rekapitulasi hasil penelitian

\begin{tabular}{lrrc}
\hline \multirow{2}{*}{\multicolumn{1}{c}{ Parameter yang diamati }} & \multicolumn{3}{c}{ Perlakuan } \\
\cline { 2 - 4 } & \multicolumn{1}{c}{ P0 } & P1 & P2 \\
\hline Konsumsi pakan (g/ekor/hari) & $518.27^{\mathrm{A}} \pm 19.37$ & $316.20^{\mathrm{B}} \pm 16.69$ & $255.13^{\mathrm{C}} \pm 13.68$ \\
Pertambahan bobot badan (g/ekor/hari) & $33.73^{\mathrm{B}} \pm 3.54$ & $39.30^{\mathrm{B}} \pm 2.27$ & $55.50^{\mathrm{A}} \pm 9.26$ \\
Konversi pakan & $15.44^{\mathrm{A}} \pm 1.17$ & $8.04^{\mathrm{B}} \pm 0.42$ & $4.70^{\mathrm{C}} \pm 0.92$ \\
\hline
\end{tabular}

Keterangan : Superskrip dengan huruf yang berbeda kearah baris menunjukan berbeda sangat nyata $(\mathrm{P}<0.01)$ 
Hasil penelitian pakan komplit berbasis hasil samping ubi kayu menunjukan pengaruh sangar nyata menurunkan konsumsi pakan, meningkatkan pertambahan bobot badan dan menurunkan konversi pakan, hal ini dipengaruhi oleh hasil samping ubi kayu mendapat teknologi pengolahan pakan yang berbentuk pellet sehingga meningkatkan densinitas pakan, meningkatkan daya cerna pakan sehingga nilai nutrisi pakan dapat diserap sesuai dengan formula ransum yang disusun.

\section{Konsumsi Pakan}

Konsumsi pakan adalah kemampuan ternak untuk menghabiskan sejumlah pakan yang diberikan dalam waktu tertentu. Konsumsi pakan dapat dihitung dengan pengurangan jumlah pakan yang diberikan dengan sisa pakan. Pakan yang diberikan selama penelitian berbentuk pellet dan hijauan segar. Pakan diberikan secara adlibitum. Konsumsi domba jantan lokal lepas sapih selama penelitian dapat dilihat pada tabel di atas.

Pemberian pakan berbasis hasil samping ubi kayu memberikan pengaruh sangat nyata terhadap konsumsi pakan, adanya pengaruh sangat nyata ini menunjukan bahwa pemberian pakan berbasis hasil samping ubi kayu dengan level 100\%. Kandungan PK pada pakan komplit yang lebih tinggi memberi pengaruh konsumsi pakan yang semakin rendah. Pengukuran konsumsi pakan dipengaruhi oleh perbedaan ternak, palatabilitas dan seleksi terhadap hijauan. Konsumsi pakan juga mempunyai hubungan dengan kebutuhan energi ternak yang sering menyebakan konsumsi pakan menjadi berbeda. Hal ini sesuai dengan pernyataan (Williamson dan Payne, 1993). Menyatakan konsumsi pakan ternak di pengaruhi oleh beberapa faktor yaitu tingkat energi, keseimbangan asam amino, tingkat kehalusan ransum, keaktifan ternak, berat badan dan kecepatan pertumbuhan.

Konsumsi pakan terendah terdapat pada $\mathrm{P} 2$ hal ini dipengaruhi oleh bentuk pakan dimana pada P2 pakan berbentuk pellet. Pakan yang berbentuk pellet tingkat konsumsinya lebih rendah dibanding dengan pakan berupa hijauan disebabkan tingkat densinitas pakan yang berbeda dimana pakan yang berbebtuk pellet tingkat densinitas lebih tinggi. Pengolahan pakan menunjukan menurunkan tingkat konsumsi pakan. Hal ini sesuai dengan pernyataan (Hoffman, 1998) yang menyatakan pengolahan pakan berbentuk pellet biasanya akan berdampak kepada peningkatan densitas nutrisi dalam pakan, peningkatan densitas pakan merupakan salah satu faktor penting untuk meningkatkan efisiensi pakan. 
Konsumsi pakan terendah terdapat pada P2 yaitu pakan diolah dalam bentuk pellet, pengolahan pakan berbasis hasil samping ubi kayu dalam bentuk pellet tidak mempengaruhi tingkat palatabilitas pakan hal ini tidak sesuai dengan pernyataan (Uden, 1988) yang menyatakan proses peletting dapat meningkatkan konsumsi, walaupun sering disertai penurun tingkat kecernaan, akibat menurunnya waktu tahan pakan dalam rumen.

Konsumsi pakan dipengaruhi oleh bentuk pakan, kandungan bahan kering yang diberikan pada ternak. Pada penelitan ini konsumsi terendah terdapat pada perlakuan P2 yaitu pakan berbentuk pellet. Pakan berbentuk pellet mempengaruhi konsumsi pakan yang semakin rendah hal ini disebabkan sekresi saliva semakin besar. Saliva yang meningkat menyebabkan mobilisasi cairan, termasuk senyawa $\mathrm{NaHCO}_{3}$ dalam jumlah besar dari sirkulasi darah menuju organ rumen yang menimbulkan hypovolemia (turunnya volume darah). Hypovolemia menjadi faktor penyebab yang menginduksi rendahnya konsumsi pakan pada awal konsumsi pakan. Hal ini sesuai dengan pernyataan (Sunagawa et al., 2005) yang menyatakan pada kambing yang diberi pakan kering dalam bentuk pelet (cube) menunjukkan bahwa sekresi saliva (air liur) dalam jumlah besar terjadi beberapa saat (10 - 30 menit) setelah mengkonsumsi pakan, lalu sekresi menurun secara signifikan.

Kandungan enrergi (TDN) pada pakan juga mempengaruhi tinggkat konsumsi pakan yaitu pada perlakuan P2 TDN lebih tinggi dibanding pada perlakuan P0 dan P1. Hal ini sesuai dengan pernyataan (Parakasi, 1999) yang menyatakan faktor lain yang membatasi konsumsi adalah kebutuhan energi (TDN) ternak tersebut. Apabila kebutuhan energi ternak telah tercukupi maka ternak akan berhenti mengkonsumsi pakan.

\section{Pertambahan Bobot Badan}

Pertambahan bobot badan adalah selisih penimbangan bobot badan akhir dengan bobot badan awal dalam satuan waktu tertentu (g/ekor/hari). Rataan pertambahan bobot badan domba jantan lokal selama penelitian.

Pemberian pakan menggunakan pakan komplit berbasis hasil samping ubi kayu dengan level $100 \%$ menunjukan pengaruh sangat nyata terhadap pertambahan bobot badan domba. Hal ini dikarenakan secara keselurahan hasil samping ubi kayu mudah terdegradasi di dalam rumen hal ini sesuai dengan pernyatan (Zinn and Depeters, 1991) yang menyatakan ubi kayu sangat mudah terdegradasi dalam rumen, inkubasi selam 24 jam kehilangan bahan kering kulit ubi kayu 
yang dikeringkan mencapai $70-73 \%$ setelah dilakukan proses ensiling, sedangkan pada pemberian rumput $100 \%$ dan campuran pakan 50\% rumput dan $50 \%$ pakan hasil samping ubi kayu tidak menunjukan perbedaan yang sangat nyata.

Pemberian pakan dengan menggunakan teknologi peleting juga meningkatkan densitas pakan dan dapat menghilangkan seleksi terhadap komponen pakan tertentu, oleh karena itu peletisasi lebih menjamin tercapai asupan nutrisi sesuai dengan yang diperhitungkan saat membuat formula ransum. Peningkatan densinitas dan menghilangkan seleksi terhadap komponen pakan berpengaruh terhadap asupan nutrisi sehingga lebih efisien dalam pertambahan bobot badan hal ini sesui dengan pernyataan (Rantan dan Ginting, 2009) yang menyatakan proses pengolahan pakan merupakan proses produksi dengan menggunakan mesin pemprosesan yang menghasilkan pakan dalam bentuk pellet, pakan yang diberikan kepada ternak bentuk komplit dinilai sangat efektif.

\section{Konversi Pakan}

Konversi pakan dapat dihitung dengan cara membandingkan antara konsumsi pakan yang diberikan dengan pertambahan bobot badan yang di dapat pada waktu yang sama. Nilai konversi paling kecil ialah pakan yang efisien. Perhitungan nilai konversi pakan dilakukan

Konversi pakan terendah terdapat pada $\mathrm{P} 2$, hal ini dipengaruhi oleh bentuk pakan yaitu pada P2 berbentuk pellet, pakan yang berbentuk pellet dapat meningkatkan asam lemak terbang, kecernaan karbohidrat. Hal ini menyebabkan asupan nutrisi terhadap ternak lebih tinggi dibanding dengan ternak yang mengkonsumsi cacahan hijauan 2-5 cm. Hal ini sesuai dengan penelitian (Ware and Zinn 2005) kombinasi cacahan (roughage) dengan tepung (konsentrat) atau kombinasi pelet

(roughage) dengan tepung (konsentrat) menunjukkan bahwa dibandingkan dengan bentuk cacahan $(2,5 \mathrm{~cm})$ penggunaan sebagai roughage berbentuk pelet dalam pakan komplit ternyata dapat meningkatkan produksi asam lemak terbang (asam propionat), kecernaan karbohidrat (pati) dalam pakan komplit, serta menekan produksi gas metana $\left(\mathrm{CH}_{4}\right)$. 


\section{KESIMPULAN}

Pemberian pakan komplit berbasis hasil samping ubi kayu memberikan pengaruh sangat nyata menurunkan konsumsipakan, meningkatkan pertambahan bobot badan dan menurunkan konversi pakan. Pakan pellet berbasis hasil samping ubi kayu dapat diberikan $100 \%$ terhadap domba.

\section{DAFTAR PUSTAKA}

Departemen Pertanian. 2009. Basis Data Pertanian. http://database.deptan.go.id/bdsp/hasil_kom_asp.

Hoffman, R.R. 1988. Anatomy of gastro-intestinal tract. In: The Ruminant Animal Digestive Physiology and Nutrition. CHURCH, D.C. (Ed.).

Parakasi,. A,1997. Ilmu Nutrisi dan Makanan Ternak Ruminan. Penerbit Universitas Indonesia, Jakarta.

Rantan krisnan dan S.P Ginting,2009. penggunaan solid ex-decanter sebagai perekat pembuatan pakan komplit berbentuk pelet jurnal Wartazoa Vol 19: 4

Sodiq dan Abidin, 2002. Penggemukan Domba. Angromedi Pustaka, Jakarta.

Sunagawa, k. nagamine. 2003. effects of parotidsaliva secretion on dry forage intake in goats. asian aust. j. sci. Sci. 1:60 - 69 .

Uden, P. 1988. The effect of grinding and pelleting hay on digestibility, fermentation rate, digesta passage and rumen and fecal particle size in cows. Anim. Feed Sci. Technol. 19: $145-157$.

Wahyu., J. 1988. Ilmu Nutrisi Ternak. Gadjah Mada University Press, Yogyakarta.

Ware, R.A. and R.A. Zinn. 2005. Effect of pelletizing on the feeding value of rice straw in steam-flaked corn growing-finishing diets for feedlot cattle. Anim. Feed Sci. Technol. 24: $631-642$.

Williamson G. dan W. J. A. Payne., 1993. Pengantar Peternakan di Daerah tropis. Terjemahan oleh : IGN Djiwa Darmadja. Gadjah Mada University Press, Yogyakarta.

Zinn, R.A. dan E.J. Depeters. 1991. Comparative feeding value of tapioca pellets for feedlot cattle. J. Anim. Sci. 69: $4726-4733$. 